Research Article

\title{
Assessment of Sleep Hygiene Practices and Sleep Quality among Nursing Officers of Selected Hospital in Delhi
}

\author{
Neelima Bisht', Bindu Shaiju', Fareha Khan ${ }^{3}$, Kuldip Kumar ${ }^{4}$ \\ ${ }^{1} \mathrm{MSc}$ Nursing (Community Health Nursing) 2nd Year Student, ${ }^{2}$ Associate Professor, ${ }^{3}$ Assistant Professor, Rufaida College of \\ Nursing, Jamia Hamdard, New Delhi, India. \\ ${ }^{4}$ Professor, Consultant \& HOD, Safdarjung Hospital, New Delhi, India.
}

DOI: https://doi.org/10.24321/2455.9318.202102

$\begin{array}{lllllll}\text { I } & \mathbf{N} & \mathbf{F} & \mathbf{O}\end{array}$

Corresponding Author:

Bindu Shaiju, Rufaida College of Nursing, Jamia

Hamdard, New Delhi, India.

E-mail Id:

bindushaiju07@yahoo.co.in

Orcid Id:

https://orcid.org/0000-0002-2574-9160

How to cite this article:

Bisht N, Shaiju B, Khan F, Kumar K. Assessment of Sleep Hygiene Practices and Sleep Quality among Nursing Officers of Selected Hospital in Delhi. Int J Nurs Midwif Res. 2021;8(1):9-13.

Date of Submission: 2021-02-09

Date of Acceptance: 2021-02-23
$\begin{array}{llllllll}\mathbf{A} & \mathbf{B} & \mathbf{S} & \mathbf{T} & \mathbf{R} & \mathbf{A} & \mathbf{C} & \mathbf{T}\end{array}$

Introduction: Nurses play a vital role in patient care and health sector. In order to meet the needs of the patients around the clock, in the nursing profession, 24 hours of the day are usually covered by three 8-hour shifts. Nurses are one subgroup of the population who appear to be especially vulnerable to poor sleep. The aim of the study was to assess sleep hygiene practices and sleep quality among nursing officers.

Methodology: A quantitative (non-experimental) research approach was adopted for the study with a descriptive survey design. The sample of the present study comprised of 100 nursing officers working in a selected hospital of Delhi. A Structured Rating Scale was used to assess the sleep hygiene practices and Pittsburgh Sleep Quality Index (PSQI) was used to assess the sleep quality of nursing officers. The data gathered were analysed and interpreted using descriptive and inferential statistics.

Results: The result of the study showed that majority of the nursing officers have poor sleep quality. Sleep hygiene practices of nursing officers were almost divided equally in fairly good and fairly poor categories. As sleep hygiene improved, sleep quality also was seen to improve. A negative correlation was seen between sleep quality and sleep hygiene practice.

Conclusion: Finding of study will act as a catalyst to carry out more extensive research on a large population sample in various settings and also a reference material for researchers who are willing to conduct research in assessing sleep quality and sleep hygiene practice.

Keywords: Sleep, Sleep Hygiene Practice, Sleep Quality

\section{Introduction}

Adequate sleep is a biological necessity, not a luxury, for normal functioning of humans. Good mental and physical health depends on the maintenance of adequate sleep. ${ }^{1}$
Nurses play a vital role in patient care, health sector, and in the health team along with other health professionals. They strive for the prevention of disease, promotion of health, and for prolonging the life of the individual and 
the community. A nurse is the co-coordinator for all the services and persons concerned with patient care.

Nursing officers are one subgroup of the population who appear to be especially vulnerable to poor sleep. Unfortunately, sleep deprivation influences their cognitive functioning, thereby affecting their performance and patient care. The high prevalence and implications of sleep difficulties among nurses warrant further exploration into underlying factors contributing to such problems.

A study with a descriptive, observational, multicenter, crosssectional design was conducted on nurses sleep quality, work environment, and quality of care in the Spanish National Health System in different shifts. The sample included 635 RN (Registered Nurses), who were working on different shift duties - day, night, and rotational shifts. The areas of work included medical, surgical, and critical care units. The analysis used was bivariate and descriptive in order to ascertain the relationship between the variables i.e. work environment, quality care, and sleep quality of nurses working in different shifts. The study concluded that there is a need for shift work in nursing, and the shift that was most commonly seen was rotating shift. Nurses on rotating shift reported the worst perception in the area of work environmental and organisational factors. Nurses on the night shift were more likely to report that the information that was relevant was lost during the changes in shifts. The nurses on rotating shifts and night shifts were less confident regarding patient self-care competence after they were discharged from hospitals. ${ }^{2}$

A sectional study was conducted to assess the sleep quality among nurses in a tertiary hospital in North-West Nigeria. The sample consisted of 100 nurses who were working with Federal Medical Centre, Kebbi State. The tools used in the study were - The Pittsburg Sleep Quality Index to determine poor sleepers and Epworth Sleepiness Scale (ESS) to determine the presence of tendency of daytime sleepiness. The study results concluded that the nurses had poor sleep quality. Although the results showed less tendency to daytime sleepiness, there is still a need to make certain changes in the job schedules of nurses like providing shorter shifts. ${ }^{3}$

A cross-sectional study was conducted to assess the quality of sleep and its associated health problems among nurses working in shifts at a tertiary care hospital in Eastern Nepal at Nobel Medical College Teaching Hospital. 148 respondents were nurses, selected from different stations of the hospital. 111 (75\%) of the 148 participant nurses in the study had Pittsburgh PSQI score of 5 or more indicating their poor sleep quality. The most common problems were gastrointestinal symptoms like nausea, stomach pain and stomach upset, followed by weight gain and back pain. Working in shift duties also affected the personal, social, and family relations of nurses. The study concluded that rotation in shift leads to poor quality of sleep among the nurses. Both the general health condition and the family and social relations are adversely affected and pose risk for the nurses. ${ }^{4}$

A cross-sectional study was conducted to determine the prevalence of sleep disturbance and its association with work characteristics among nurses in a Government Hospital in Malaysia. The objective of the study was to determine the prevalence of sleep disturbance and to associate it with work characteristics of nurses in the Melaka Hospital, Malaysia. Universal sampling was utilised and data were collected using the Malay version of the tool i.e., Pittsburgh Sleep Quality Index (PSQI) questionnaire. The study revealed that there was a moderate prevalence of sleep disturbance among nurses. But the prevalence of sleep disturbance was not associated with the work in shifts. The factors associated with reduced global sleep quality were identified to be age, marital status, and work environment, mainly the intensive group unit. $^{5}$

A cross-sectional study was done with the objective of testing the moderating and mediating effects of sleep hygiene practice on the relationship between severity of anxiety and insomnia among nurses working in a hospital in Taiwan. In the study, higher severity of insomnia was found among nurses who had more anxiety and more insomnia was found among nurses with poor sleep hygiene practice. It was found that the effects of anxiety on the severity of insomnia were partially mediated by sleep hygiene practices.

Further, it was seen that sleep hygiene practice was a moderator in the relationship between anxiety and severity of insomnia, with covariates as age and work units. Training nurses on sleep hygiene practices can enhance and promote better sleep hygiene, thereby reducing the risk of insomnia among nurses. ${ }^{6}$

Many workers today have jobs requiring them to work in shifts, some of which go around the clock. Shift work is a common occupational stressor that affects blood pressure, metabolic rate, blood sugar levels, mental efficiency, and work motivation. Shift work also influences sleep patterns, family, and social life. Night shift can have a negative impact as it disturbs the sleep-wake cycle, changes eating habits, and in the long run causes severe gastrointestinal disturbances, neuro-psychic problems, chronic fatigue, anxiety, depression, and probably hypertension and heart attack. Nurses are one subgroup of the population who appear to be especially vulnerable to poor sleep. The high prevalence and implications of sleep difficulties among nurses warrant further exploration into underlying factors contributing to such problems. In the present setting, the investigator observed that the nurses who work night shifts 
have emotional and physiological problems with their shift rotation and have insufficient time for family and rest. So it was felt by the investigator that there was a need for a study to assess the sleep quality among nurses working night shifts.

\section{Objectives of the Study}

- To assess sleep hygiene practices of nursing officers

- To assess sleep quality of nursing officers

- To identify the relationship between sleep hygiene practices and sleep quality among nursing officers

\section{Materials and Methods}

Quantitative (non-experimental) approach with a descriptive survey design was employed for the study. The setting for the study was Vardhmam Mahavir Medical College \& Safdarjung Hospital, New Delhi. In the present study, the sample comprised 100 nursing officers working in general wards of VMMC \& Safdarjung Hospital, New Delhi. Nonprobability, convenient sampling technique was adopted to select samples. Female nurses who were working for at least 6 months and in the general wards of the selected hospital were included in the study. On the other hand, those who were not willing to participate in the study and those who were working in ICU, OT, and other emergency departments were excluded from the study. Data were collected for the duration of a month.

After obtaining ethical clearance to conduct the research study from the ethical committee of the Institutional Review Board, Jamia Hamdard, formal permission for conducting research was obtained from the selected hospital of Delhi. Written informed consent was taken from each study subject. They were assured of anonymity and confidentiality of the information provided during the study. The final study was conducted in VMMC \& Safdarjung Hospital, New Delhi. The subjects included nursing officers working in general wards of the selected hospital. The information was gathered using a structured questionnaire to assess sleep hygiene practices and Pittsburgh Sleep Quality Index (PSQI), a standardised tool was used to assess the sleep quality of nursing officers. To ensure validity of the structured questionnaire, it was given to 9 experts from the field of Medical-Surgical Nursing, Mental Health Nursing, Medicine, Neurology, and Psychiatry. The reliability of the structured questionnaire to assess sleep hygiene practices was assessed using test-retest method, and $r=0.8$ was obtained that assured the reliability of the tool.

\section{Results}

\section{Section I: Sample Characteristics}

This section highlights the sample characteristics of nursing officers. The data was computed using frequency and percentage as shown in Table 1.
Table I.Frequency Percentage of Sample Characteristics of Nursing Officers

$(\mathrm{N}=100)$

\begin{tabular}{|c|c|c|c|}
\hline $\begin{array}{l}\text { S. } \\
\text { No. }\end{array}$ & \multicolumn{2}{|c|}{ Sample Characteristics } & $\begin{array}{l}\text { Frequency/ } \\
\text { Percentage }\end{array}$ \\
\hline \multirow{4}{*}{1.} & \multirow{4}{*}{$\begin{array}{l}\text { Age (in } \\
\text { years) }\end{array}$} & $18-25$ & 1 \\
\hline & & $25-32$ & 34 \\
\hline & & $32-39$ & 51 \\
\hline & & Above 39 & 14 \\
\hline \multirow{2}{*}{2.} & \multirow{2}{*}{$\begin{array}{l}\text { Marital } \\
\text { status }\end{array}$} & Married & 100 \\
\hline & & Unmarried & 0 \\
\hline \multirow{3}{*}{3.} & \multirow{3}{*}{ Education } & GNM & 65 \\
\hline & & $\mathrm{BSC}$ & 32 \\
\hline & & MSc & 3 \\
\hline \multirow{5}{*}{4.} & \multirow{5}{*}{$\begin{array}{l}\text { Duration of } \\
\text { experience }\end{array}$} & 6 months- 5 years & 23 \\
\hline & & $5-10$ years & 35 \\
\hline & & $10-15$ years & 21 \\
\hline & & $15-20$ years & 15 \\
\hline & & More than 20 years & 6 \\
\hline \multirow{3}{*}{5.} & \multirow{3}{*}{$\begin{array}{l}\text { Duration of } \\
\text { night shift }\end{array}$} & $6-8$ hours & 9 \\
\hline & & 8-12 hours & 67 \\
\hline & & More than 12 hours & 24 \\
\hline \multirow{3}{*}{6.} & \multirow{3}{*}{$\begin{array}{l}\text { Night shift } \\
\text { in a month }\end{array}$} & 3-6 nights & 42 \\
\hline & & $6-9$ nights & 44 \\
\hline & & 9-12 nights & 14 \\
\hline \multirow{4}{*}{7.} & \multirow{4}{*}{$\begin{array}{l}\text { Number of } \\
\text { children }\end{array}$} & Nil & 17 \\
\hline & & 1 & 28 \\
\hline & & 2 & 49 \\
\hline & & More than 2 & 6 \\
\hline \multirow{5}{*}{8.} & \multirow{5}{*}{$\begin{array}{c}\text { Age of } \\
\text { youngest } \\
\text { child }\end{array}$} & 6 months- 5 years & 32 \\
\hline & & $5-10$ years & 28 \\
\hline & & $10-15$ years & 10 \\
\hline & & Above 15 years & 13 \\
\hline & & Not applicable & 17 \\
\hline \multirow{3}{*}{9.} & \multirow{3}{*}{$\begin{array}{l}\text { Domestic } \\
\text { help }\end{array}$} & Part time & 37 \\
\hline & & Full time & 22 \\
\hline & & None & 41 \\
\hline \multirow{4}{*}{10.} & \multirow{4}{*}{$\begin{array}{l}\text { Type of } \\
\text { family }\end{array}$} & Joint family & 42 \\
\hline & & Nuclear family & 46 \\
\hline & & Single parent family & 11 \\
\hline & & Extended family & 1 \\
\hline
\end{tabular}


Table 2.Range of Obtained Scores, Frequency, Percentage, Mean, Median, Standard Deviation of Sleep Quality Index of Nursing Officers

\begin{tabular}{|c|c|c|c|c|c|}
\hline Range of Scores & $\begin{array}{c}\text { Range of } \\
\text { Obtained Scores }\end{array}$ & Frequency/ Percentage & Mean & Median & Standard Deviation \\
\hline Good sleep quality (0-4) & \multirow{2}{*}{$1-16$} & 39 & \multirow{2}{*}{5.58} & \multirow{2}{*}{5} & \multirow{2}{*}{2.454} \\
\hline Poor sleep quality ( $\geq 5$ ) & & 61 & & & \\
\hline
\end{tabular}

Table 3.Range of Scores, Range of Obtained Score, Frequency, Percentage, Mean, Median, Standard Deviation of Sleep Hygiene Practices of Nursing Officers

$(\mathrm{N}=100)$

\begin{tabular}{|c|c|c|c|c|c|}
\hline Range of Scores & $\begin{array}{c}\text { Range of } \\
\text { Obtained Scores }\end{array}$ & $\begin{array}{l}\text { Frequency/ } \\
\text { Percentage }\end{array}$ & Mean & Median & Standard Deviation \\
\hline $\begin{array}{c}\text { Poor sleep } \\
\text { hygiene practice }(0-16)\end{array}$ & \multirow{4}{*}{$19-50$} & 0 & \multirow{4}{*}{33.4} & \multirow{4}{*}{33} & \multirow{4}{*}{5.705} \\
\hline $\begin{array}{c}\text { Fairly poor sleep } \\
\text { hygiene practice (17-32) }\end{array}$ & & 48 & & & \\
\hline $\begin{array}{c}\text { Fairly good sleep } \\
\text { hygiene practice (33-48) }\end{array}$ & & 51 & & & \\
\hline $\begin{array}{l}\text { Good sleep } \\
\text { hygiene practice (49-64) }\end{array}$ & & 1 & & & \\
\hline
\end{tabular}

Table 4.Mean, Median, Standard Deviation, and 'r' Value for Correlation of Sleep Quality and Sleep Hygiene Practice

\begin{tabular}{|c|c|c|c|c|}
\hline Variable & Mean & Median & Standard Deviation & 'r' \\
\hline Sleep quality & 5.58 & 5 & 2.45 & \multirow{2}{*}{-0.211} \\
\hline Sleep hygiene practice & 33.4 & 33 & 5.705 & \\
\hline
\end{tabular}

\section{Section II: Sleep Quality of Nursing Officers}

This section describes the sleep quality of nursing officers that was obtained using the Pittsburgh Sleep Quality Index (PSQI), which has been shown in Table 2.

\section{Section III: Sleep Hygiene Practices of Nursing Officers}

This section comprises data pertaining to sleep hygiene practices of nursing officers (Table 3 ) obtained using the structured questionnaire.

\section{Section IV: Relationship between Sleep Quality and Sleep Hygiene Practices of Nursing Officers}

This section highlights the relationship between sleep quality and hygiene practices of nursing officers obtained using the coefficient of correlation, as shown in Table 4.

Data presented in Table 4 show that the coefficient of correlation $(r)$ between sleep quality and sleep hygiene practice is -0.211 and ' $r$ ' (98) is 0.195 . Since the computed value $(-0.211)$ is less than the table value $(0.195)$ at 0.05 level of significance, it is indicated that there is no significant correlation between sleep hygiene practice and sleep quality scores of nursing officers. The value of ' $r$ ' (-0.211) shows a negative correlation between sleep hygiene practice and sleep quality scores of nursing officers.

\section{Discussion}

The present study assessed sleep quality and sleep hygiene practices of nursing officers working in shift duties. Shift workers are known to be associated with various medical conditions and they have poor quality of sleep.

The result of this study revealed that majority of the nursing officers have poor sleep quality. The data indicated that out of 100 study subjects, $61 \%$ were found to be having poor sleep quality and the rest (39\%) had good sleep quality ( $n=$ 100). Consistent with this study finding is a cross-sectional study conducted to assess the quality of sleep and its associated health problems among nurses working in shifts at tertiary care hospital in Eastern Nepal at Nobel Medical College Teaching Hospital. 148 respondents were nurses selected from different stations of the hospital. 111 (75\%) of the 148 participant nurses in the study had Pittsburgh PSQI 
score of 5 or more indicating their poor sleep quality. The most common problems were gastrointestinal symptoms like nausea, stomach pain, and stomach upset, followed by weight gain and back pain. Working in shift duties also affected the personal, social and family relations of the nurses. The study concluded that rotation in shift leads to poor quality of sleep among the nurses. ${ }^{4}$

A cross-sectional study was conducted to assess sleep quality among nurses in a tertiary hospital in North-West Nigeria. The sample consisted of 100 nurses who were working with Federal Medical Centre, Kebbi State. The tool used in the study was -The Pittsburg Sleep Quality Index to determine poor sleepers and Epworth Sleepiness Scale (ESS) was used to determine the presence of the tendency of daytime sleepiness. The study results concluded that the nurses had poor sleep quality. ${ }^{3}$ The present study findings are consistent with this study.

The data of the present study indicated that out of 100 study subjects, $51 \%$ were found to be having fairly good sleep hygiene practice, $48 \%$ had poor sleep hygiene practice, and the rest (1\%) had good sleep hygiene practice. Similar patterns are seen in the studies to test the mediating and moderating effects of sleep hygiene practice on the relationship between anxiety and insomnia severity in hospital nurses of Taiwan. The results indicated that nurses with more anxiety tended to have higher insomnia severity. Further, nurses with poor sleep hygiene practices had more insomnia. Sleep hygiene practice partially mediated the effects of anxiety on insomnia severity. ${ }^{6}$

\section{Conclusion}

Nurses working in shift duties play a crucial role in providing 24/ 7 medical services in a hospital. Shift workers are known to be associated with various medical conditions and they have poor quality of sleep. The findings from the present study reveal that majority of the nursing officers have poor sleep quality. Sleep hygiene practices of nursing officers were almost equally divided in fairly good and fairly poor categories. As sleep hygiene improved, sleep quality also was seen to improve. A negative correlation was seen between sleep quality and sleep hygiene practice.

The studies found that sleep quality and sleep hygiene is correlated and improvisation is essential keeping in view that nurses have a major contribution in patient care. The sleep quality affects their work performance, hence can lead to errors and risks in providing service to the patients. Nurses can practice good adaptive hygiene behaviours to improve the quality of sleep. Campaign, awareness, in-service classes and continuing education programmes can be organised for shift working nurses for promoting good sleep. Nurses must be well trained for imparting knowledge to their patients with regard to maintaining and promoting good sleep. Student nurses can use evidence-based knowledge to understand the process of good or bad quality of sleep. Nursing curriculum can include content on sleep quality and sleep hygiene practices. Nursing administration must facilitate the organisation and conduction of programmes in wards promoting effective sleep for patients, nurses and other target groups. Furthermore they must ensure that the protocol for the provision of duty offs after shift duties and avoidance of extended shift duties are take care of, so as to promote effective sleep quality among the nurses. Finding of study will act as a catalyst to carry out more extensive research on a large population sample in various settings and also a reference material for researchers who are willing to conduct research in assessing sleep quality and sleep hygiene practice.

\section{Source of Funding: None \\ Conflict of Interest: None \\ References}

1. Brown FC, Buboltz WC, Soper B. Development and evaluation of the sleep treatment and education program for students (STEPS). J Am Coll Health. 2006;54:231-36. [Google Scholar]

2. Gómez-García T, Ruzafa-Martínez M, Fuentelsaz-Gallego C, Madrid JA, Rol MA, Martínez-Madrid MJ, MorenoCasbas T; SYCE and RETICEF Group. Nurses' sleep quality, work environment and quality of care in the Spanish National Health System: observational study among different shifts. BMJ Open. 2016;6(8):e012073. [PubMed] [Google Scholar]

3. Aliyu I, Ibrahim ZF, Teslim LO, Okhiwu H, Peter ID, Michael GC. Sleep quality among nurses in a tertiary hospital in North-West Nigeria. Niger Postgrad Med J. 2017;24(3):168. [PubMed] [Google Scholar]

4. Thapa D, Malla G, KC A. Sleep quality and related health problems among shift working nurses at a tertiary care hospital in Eastern Nepal: a cross-sectional study. J Nurs Health Stud. 2017;2(3).

5. Nazatul SM, Saimy I, Moy FM, Nabila AS. Prevalence of sleep disturbance among nurses in a Malaysian government hospital and its association with work characteristics. J Univ Malaya Med Cent. 2008;11(2):6671. [Google Scholar]

6. Chou TL, Chang $\mathrm{LI}$, Chung $\mathrm{MH}$. The mediating and moderating effects of sleep hygiene practice on anxiety and insomnia in hospital nurses. Int J Nurs Pract. 2015;21(52):9. [PubMed] [Google Scholar] 